\title{
The impact of renal function on clinical and biochemical characteristics in advanced heart failure patients
}

\author{
Michał Bohdan ${ }^{1,2}$ (D) Anna Frankiewicz ${ }^{1}$, Marcin Gruchała ${ }^{1,2}$ (D)
}

${ }^{1}$ First Department of Cardiology, Medical University of Gdańsk, Poland

${ }^{2}$ Clinical Centre of Cardiology, University Clinical Centre, Gdańsk, Poland

\begin{abstract}
Background: Coexistence of heart failure with reduced ejection fraction (HFrEF) and chronic kidney disease is associated with poor prognosis. We assessed the effect of renal function on exercise capacity and clinical parameters of patients with HF. Materials and methods: Forty five patients aged $58.2 \pm 10.6$ years with stable severe HFrEF were recruited. Patients were divided into 3 groups: group 1 - eGFR: $30-59 \mathrm{ml} / \mathrm{min} / 1.73 \mathrm{~m} 2$; group 2 eGFR: $60-89 \mathrm{ml} / \mathrm{min} / 1.73 \mathrm{~m} 2$ and group 3 - eGFR: $\geq 90 \mathrm{ml} / \mathrm{min} / 1.73 \mathrm{~m} 2$. Biochemical analysis, echocardiography, 6-minute walking test and cardiopulmonary stress testing were performed. Results: Patients in group 1 were significantly older than patients in group $3(60.4 \pm 11$. 1 years vs. $49.25 \pm 11.2$ years, respectively, $p<0.05)$. Patients in group 2 had significantly higher BMI in comparison to group 3 ( $29.8 \pm 4.4$ vs. $25.1 \pm 4.2$; $p<0.05)$. Interestingly, patients in group 1 had significantly lower peak oxygen uptake $(10.2 \pm 3.1 \mathrm{ml} / \mathrm{kg} / \mathrm{min} \mathrm{vs} .16 .1 \pm 3.5 \mathrm{ml} / \mathrm{kg} / \mathrm{min}$, $\mathrm{p}<0.05)$ and oxygen uptake at anaerobic treshold $(7.9 \pm 2.4 \mathrm{ml} / \mathrm{kg} / \mathrm{min}$ vs. $10.7 \pm 1.9 \mathrm{ml} / \mathrm{kg} / \mathrm{min}, p<0.05)$. Conclusions: Diminished renal function in patients with stable, advanced HFrEF may be associated with significantly worse peak VO2 and VO2 in AT.

Keywords: heart failure / kidney disease / exercise capacity
\end{abstract}

\section{Citation}

Bohdan M, Frankiewicz A, Gruchała M. The impact of renal function on clinical and biochemical characteristics in advanced heart failure patients. Eur J Transl Clin Med. 2018;1(2):17-22.

DOI: $10.31373 /$ ejtcm/102804

\section{Background}

Heart failure with reduced left ventricular ejection fraction (HFrEF) is becoming a common disease and its prevalence is rising due to ageing of the population and improvements in cardiovascular disease management [1]. In the last decades there has been a significant progress in pharmacotherapy ( $\beta$-blockers, angiotensin con- 
verting enzyme inhibitors (ACE-I), angiotensin receptor blockers (ARBs), angiotensin receptor blocker in combination with neprylisin inhibitor (ARNI), ivabradine) and cardiac devices. Despite these advancements the prognosis in HFrEF is still poor. In addition, HFrEF may be associated with various comorbidities which also affect the morbidity and mortality and reduce the quality of life [3]. Chronic kidney disease is regarded as one of the comorbidities of a particular importance and its relationship with HFrEF has been recognized as cardio-renal syndrome [4-5]. Impaired renal function not only affects the HF prognosis but also may have an impact on the pharmacotherapy especially in advanced stages of renal failure. Furthermore, some studies suggested that even small increase in serum creatinine levels in HF patients is associated with worse outcome [6-7].

The aim of the study was to investigate the potential effect of decreased estimated glomerular filtration rate (eGFR) on exercise capacity and clinical and biochemical parameters in stable advanced chronic HFrEF.

\section{Material and methods}

This retrospective, single-centre study was performed 45 patients with severe chronic heart failure with reduced left ventricular ejection fraction evaluated for potential heart transplantation. All patients received pharmacotherapy for at least 6 months with $\beta$-blocker, ACE-I or ARB and aldosteron blocker and also ivabradine, diuretics and digoxin if indicated. The inclusion criteria were as follows: ischaemic or nonischaemic HFrEF for at least 1 year, NYHA II or III, stable course of the disease defined as no increase in symptoms severity and/or no modification of treatment for at least 3 months prior to inclusion, LVEF $\leq 35 \%$ in two-dimensional echocardiography during evaluation, at least one HFrEF decompensation within 12 months prior to inclusion and age $\geq 18$ years old. Whereas valvular heart disease as a main cause of HF, eGFR $\leq 30 \mathrm{ml} / \mathrm{kg} / 1.73 \mathrm{~m} 2$, neurological disorders, inability to perform exercise tests, and frailty were the exclusion criteria.

Patients were divided into 3 groups based on their initial renal function: group 1: eGFR $30-59 \mathrm{ml} / \mathrm{kg} / 1.73$ $\mathrm{m} 2, \mathrm{n}=18$; group 2: eGFR 60-89 ml/kg/1.73 m2, $\mathrm{n}=19$; and group 3: eGFR $\geq 90 \mathrm{ml} / \mathrm{kg} / 1.73 \mathrm{~m} 2, \mathrm{n}=8$. In each group the following tests were performed: laboratory analysis, electrocardiogram, echocardiography, 6-minute walking test, cardiopulmonary stress testing. In addition, prognosis was assessed using the Seattle Heart Failure Risk Model [1].

GFR was estimated using the Modification of Diet in Renal Disease (MDRD) formula. Anaemia was diagnosed according to the World Health Organization criteria (hemoglobin $<13 \mathrm{~g} / \mathrm{dL}$ in males and $<12 \mathrm{~g} / \mathrm{dL}$ in females).
The 6-minute walking test (6MWT) was performed in each patient. The patients were allowed to self-pace and rest as needed during 6 minutes walking along a marked walkway.

Cardiopulmonary stress testing (CPET) was performed in each patient using Medisoft Ergocard (Belgium). Patients underwent maximal, symptom-limited test with exercise bicycle using the ramp protocol $(10 \mathrm{~W} / \mathrm{min})$. Patients were asked to fast for 4 hours before the test. The gas exchange data were collected throughout the test with a metabolic cart. The following parameters were assessed during CPET: blood pressure, heart rate, respiratory rate, electrocardiogram monitoring, symptoms, and arrhythmias. Gas exchange variables assessment included measurement of: $\mathrm{CO} 2$ production (VCO2), oxygen consumption (VO2), and minute ventilation.

The study protocol was approved by the local bioethics committee.

All data are presented as mean \pm SD. Kolmonogrov-Smirnov test was used to assess the normal distribution. Analysis of variance (ANOVA) with Tukey's post hoc and Chi-squared test were performed. Statistical analysis was done using Statistica 13 software. $P$ value $<0.05$ was considered statistically significant.

\section{Results}

The mean age of the study group was $58.2 \pm 10.6$ years and mean LVEF was: $23.1 \pm 6.3 \%$. Patients in group 1 and 2 were significantly older than in group 3 $(60.4 \pm 11.1$ years and $59.8 \pm 8.2$ vs. $49.3 \pm 11.2$ years respectively, $p<0.05$ for both interactions). The majority of patients in all sub-groups were male. Concomitant disease prevalence is presented in Table 1 . There were no significant differences in pharmacotherapy between the study groups.

Patients in group 2 had significantly higher BMI in comparison to group $3(29.8 \pm 4.4 \mathrm{~kg} / \mathrm{m} 2$ vs. $25.1 \pm$ $4.2 \mathrm{~kg} / \mathrm{m} 2, \mathrm{p}<0.05)$. No differences in BMI were found between group 1 and 3 . In addition, the prognosis assessed using the Seattle Heart Failure Risk Model was similar in the analysed groups (Table 1).

Moreover, hemoglobin level was significantly lower in group 1 in comparison to group 2 and 3 (13.5 $\pm 1.7 \mathrm{~g} / \mathrm{l}$ vs. $14.6 \pm 1.4 \mathrm{~g} / \mathrm{l}$ and $14.9 \pm 0.8 \mathrm{~g} / \mathrm{l}$, respectively, $\mathrm{p}<0.05$ for both interactions). Furthermore, there was a tendency towards higher prevalence of anaemia in group 1 in comparison to other 2 groups (38.9\% vs. $15.8 \%$ and $0 \%$ respectively, $\mathrm{p}=0.059$ ). In addition, uric acid level was significantly higher in group 1 in comparison to group $3(10.2 \pm 2.3 \mathrm{mg} / \mathrm{dl}$ vs. $7.4 \pm 2.2 \mathrm{mg} / \mathrm{dl}, \mathrm{p}<0.05)$. The other laboratory, clinical and echocardiographic parameters are summarized in Table 2. 
Table 1. Characteristics of patients based on renal function

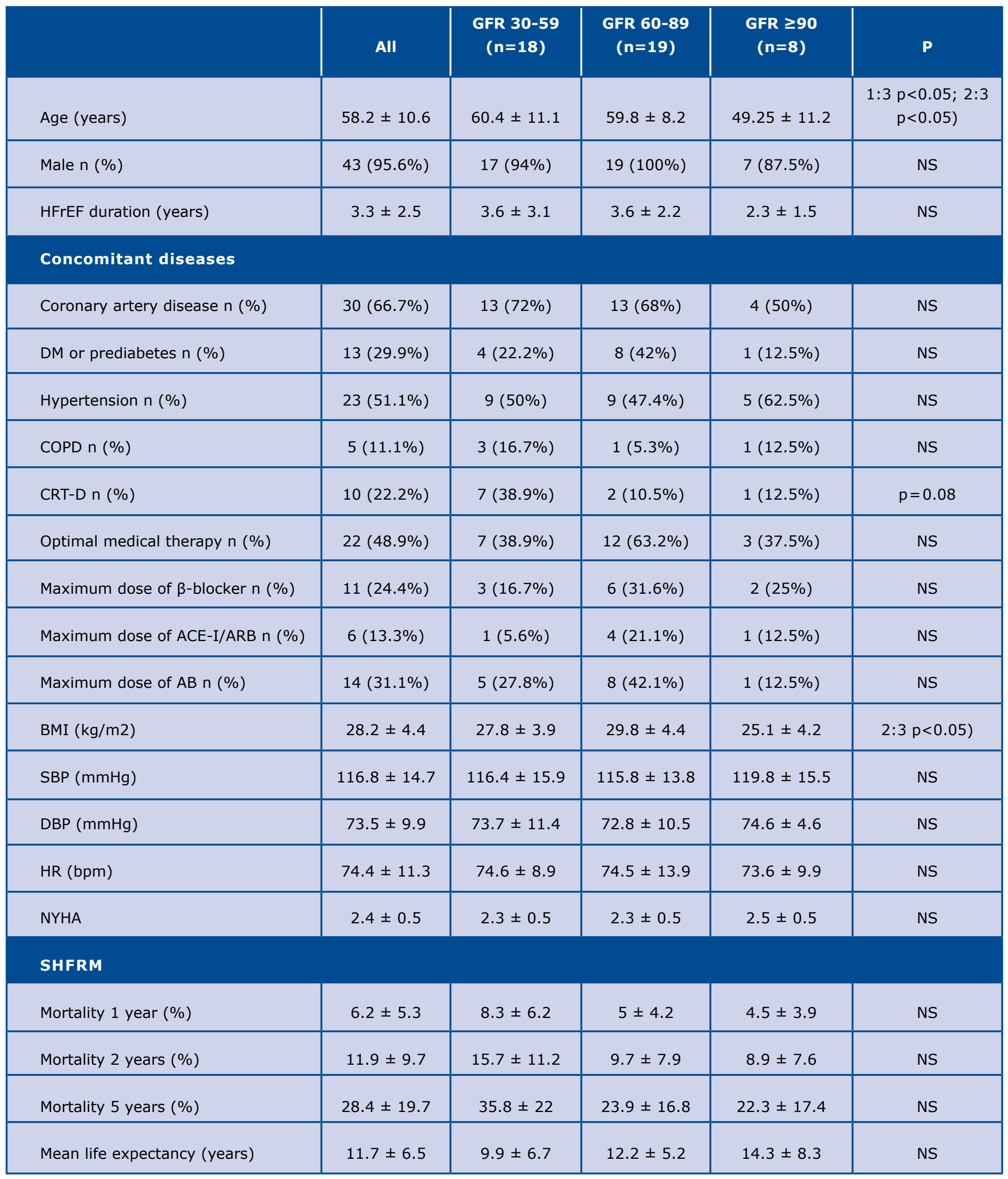




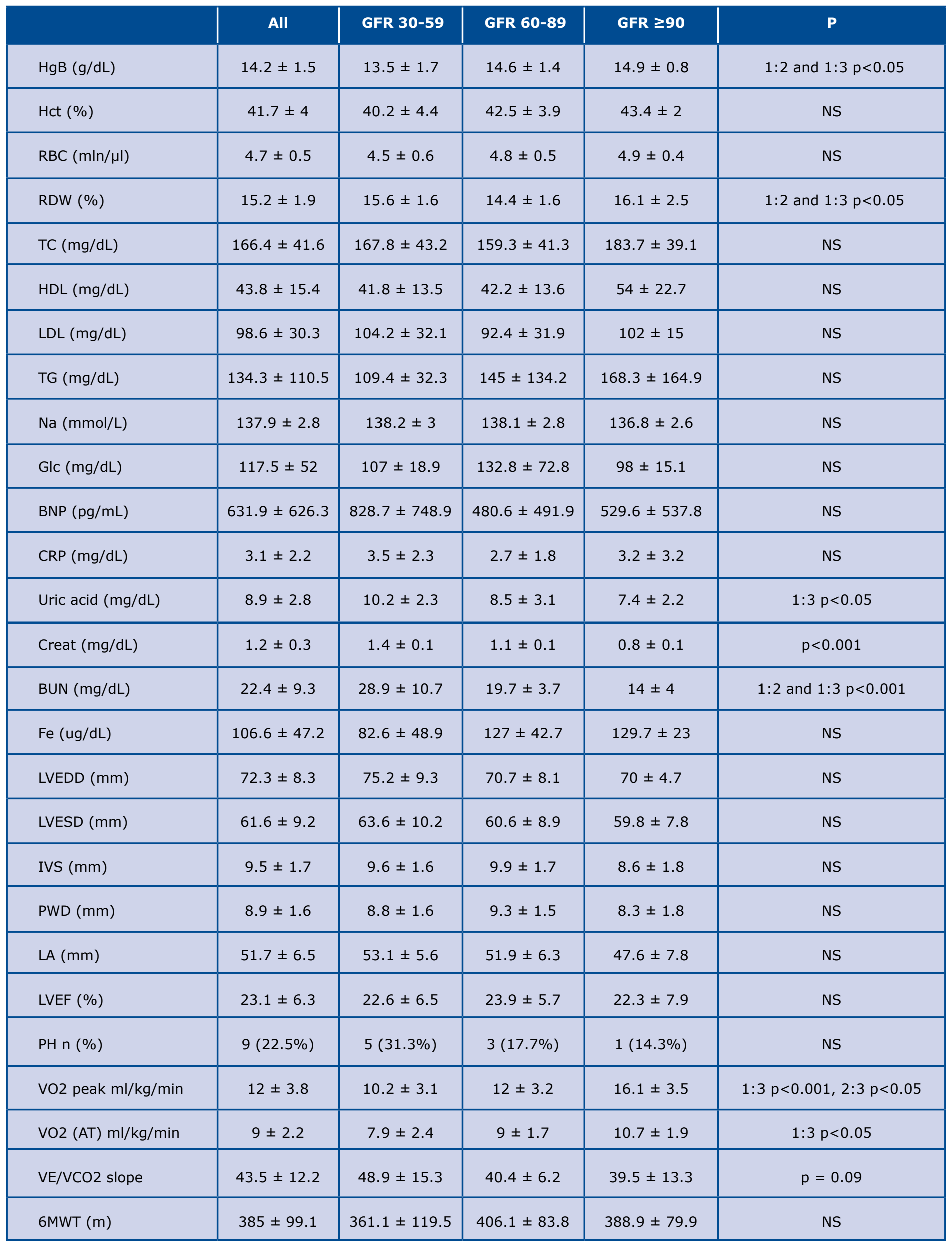




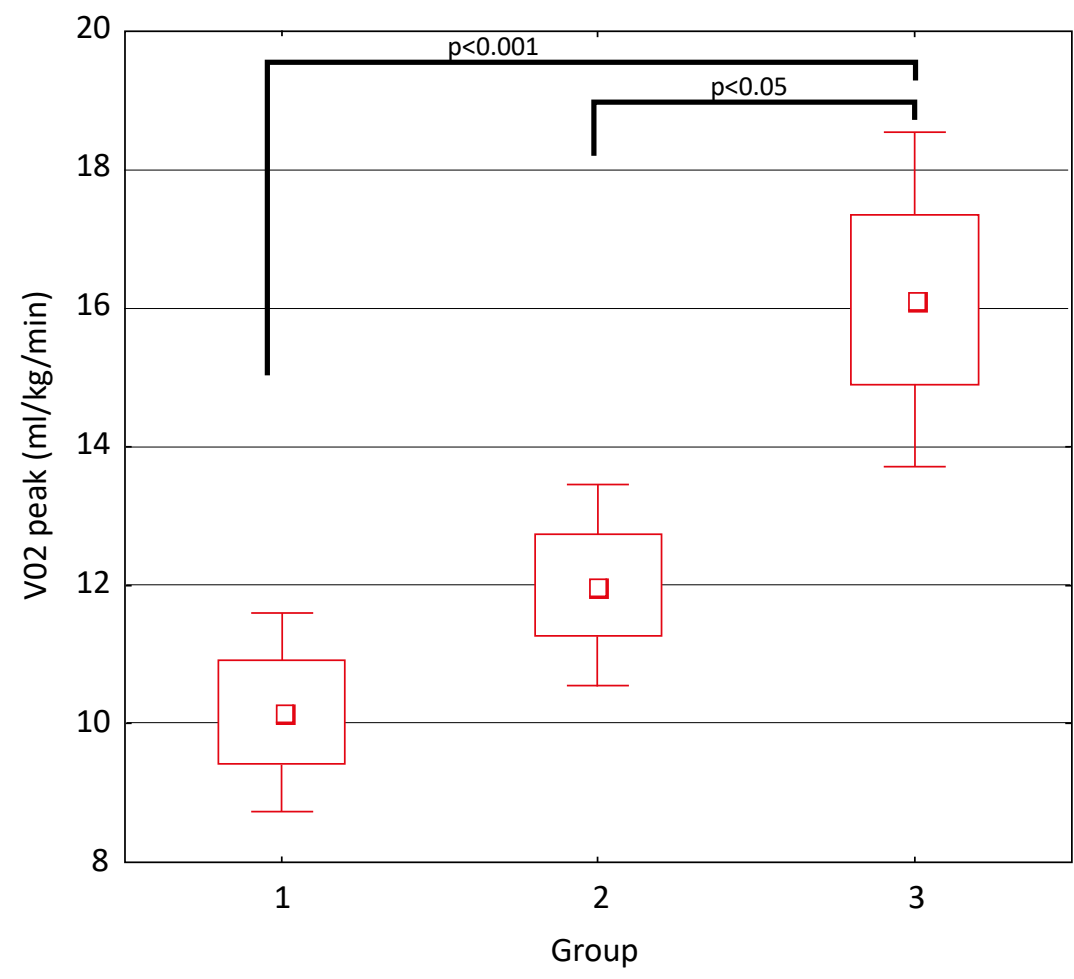

(1-GFR:20-59 ml/min/1.73m2; 2-GFR:60-89 ml/min/1.73m2;

Interestingly, patients in group 1 and 2 had significantly lower peak VO2 in comparison to group 3 (10.2 $\mathrm{ml} / \mathrm{kg} / \mathrm{min} \pm 3.1$ and $12 \pm 3.2 \mathrm{ml} / \mathrm{kg} / \mathrm{min}$ vs. $16.1 \pm 3.5$ $\mathrm{ml} / \mathrm{kg} / \mathrm{min}, \mathrm{p}<0.001$ and $\mathrm{p}<0.05$, respectively). Similarly, VO2 in anaerobic threshold (AT) was significantly lower in group 1 in comparison to group 3 (7.9 \pm 2.4 $\mathrm{ml} / \mathrm{kg} / \mathrm{min}$, vs. $10.7 \pm 1.9 \mathrm{ml} / \mathrm{kg} / \mathrm{min}, \mathrm{p}<0.05$ ) (Figure 1 ). No changes in 6MWT distance or VE/VCO2 slope were observed.

\section{Discussion}

Renal dysfunction is becoming a common abnormality in cardiovascular diseases and its burden may be often seen in HFrEF patients [8-9]. In our study, patients with chronic kidney disease with eGFR $<60 \mathrm{ml} / \mathrm{min} / 1.73$ $\mathrm{m} 2$ had more advanced age in comparison to other 2 groups. Katsanos et al. observed that there was a strong association between increasing age and comorbidities that affected the short-term survival [10]. In addition, in their study on HFrEF patients aged $>65$ years old Braunstein et al. found that nearly $40 \%$ of them had $>5$ non-cardiac comorbidities [11]. Furthermore, older patients with many comorbities experienced much more adverse events requiring hospitalizations than the younger HFrEF patients [11]. In our study only non-sinus rhythm prevalence was significantly higher in group 1 than in other groups. However, no statistically significant differences in the prevalence of other comorbidities were noted.

In addition, we found significantly lower hemoglobin levels in group 1 (with more advanced renal disease) in comparison to the other two groups. This observation is supported by literature [12-14]. The socalled „renal anaemia” is in the majority of cases a consequence of endogenous erythropoetin deficiency [12]. Furthermore, anaemia in HFrEF is also common and its origin is multifactoral [15]. In our study we observed a tendency towards higher anaemia prevalence in group 1 . Since data concerning anaemia etiology were not assessed in our study, we cannot provide further details on this issue. We also observed that patients in group 1 had significantly higher concentration of uric acid when compared to group 3. Fillipatos and al. reported that hyperuricaemia is associated with poor outcomes in HFrEF patients with normal renal function but has no effect in patients with chronic kidney disease [16]. High concentration of uric acid in HFreEF patients with kidney disease is a consequence of impaired uric acid excretion in kidneys [16].

In our study we found that patients in group 1 had significantly lower mean peak VO2 and VO2 in AT in comparison to other two groups. No significant differences in VE/VCO2 slope and 6MWT were noted. Ebner et al. observed a significant reduction in exercise capacity cor- 
relating with decreasing hemoglobin levels $(r=0.24, p<$ 0.001) [17]. In addition, our results were similar to the study by Hotta's et al. in which HF patients who attained an exercise capacity of $\geq 5$ METs were younger and had higher hemoglobin and eGFR level in comparison to patients with exercise capacity <5 METs. [18]. However the patients enrolled in Hotta's study had less advanced HFrEF with higher LVEF and lower BNP level than our study group. Moreover, Scrutinio et al. recruited 2,938 HFrEF patients who underwent cardiopulmonary stress test [19]. They observed that renal disease significantly correlated with peak VO2. Patients with renal dysfunction (eGFR $<45 \mathrm{ml} / \mathrm{min} / 1.73 \mathrm{~m} 2$ ) were older and had a more advanced NYHA class, lower SBP and hemoglobin values, and higher BNP concentrations in comparison to patients with better renal function [19].

Our study has some limitations. The study group was relatively small and was recruited in one clinical centre. On the other hand, we recruited only patients with advanced, stable HFrEF - a population of patients with less evidence in terms of renal function and ex- ercise capacity in comparison to other HFrEF patients. Moreover, we observed only 3 cardiovascular deaths during a 8-month follow-up. Therefore, it was not possible to perform any survival analysis in the study group. Our findings must be interpreted with caution and need further evaluation in large clinical trials focusing on advanced heart failure patients.

Conclusions

Chronic kidney disease in advanced HFrEF may have a significant impact on peak VO2 and VO2 in AT but not on VE/VCO2 slope and 6MWT.

\section{Acknowledgements}

The Authors declare no conflict of interest.

The study was supported by Medical University of Gdansk grant ST02-0085/07/182.

\section{References}

1. Metra M, Teerlink JR. Heart failure. Lancet. 2017;390(10106):1981-95.

2. Levy WC, Mozaffarian D, Linker DT, Sutradhar SC, Anker SD, Cropp AB, et al. The Seattle Heart Failure Model: prediction of survival in heart failure. Circulation. 2006;113(11):1424-33.

3. van der Wal HH, van Deursen VM, van der Meer P, Voors AA. Comorbidities in Heart Failure. In: Brazilian Journal of Medical and Biological Research. 2017. p. 35-66.

4. Kirchhof P, Benussi S, Kotecha D, Ahlsson A, Atar D, Casadei B, et al. 2016 ESC Guidelines for the management of atrial fibrillation developed in collaboration with EACTS. Eur Heart J. 2016 Oct 7;37(38):2893-962.

5. Shlipak MG, Massie BM. The Clinical Challenge of Cardiorenal Syndrome. Circulation. 2004;110 (12):1514-7.

6. Gottlieb SS, Abraham W, Butler J, Forman DE, Loh E, Massie BM, et al. The prognostic importance of different definitions of worsening renal function in congestive heart failure. J Card Fail. 2002;8(3):136-41.

7. Damman $\mathrm{K}$, Valente MAE, Voors AA, O'connor CM, van Veldhuisen DJ, Hillege HL. Renal impairment, worsening renal function, and outcome in patients with heart failure: an updated meta-analysis. Eur Heart J. 2013;35(7):455-69.

8. Grande D, Gioia MI, Terlizzese P, lacoviello M. Heart Failure and Kidney Disease. In: Heart Failure: From Research to Clinical Practice: Volume 3. Springer; 2017. p. 219-38.

9. Chong VH, Singh J, Parry H, Saunders J, Chowdhury F, Mancini DM, et al. Management of Noncardiac Comorbidities in Chronic Heart Failure. Cardiovasc Ther. 2015;33(5):300-15.

10. Katsanos S, Bistola V, Parissis JT. Acute heart failure syndromes in the elderly: The European Perspective. Heart Fail Clin. 2015;11(4):637-45.

11. Braunstein JB, Anderson GF, Gerstenblith G, Weller W, Niefeld M, Herbert R, et al. Noncardiac comorbidity increases preventable hospitalizations and mortality among Medicare beneficiaries with chronic heart failure. J Am Coll Cardiol. 2003;42(7):1226-33.

12. Mimura I, Tanaka T, Nangaku M. How the Target Hemoglobin of Renal Anemia Should Be? Nephron. 2015;131(3):202-9.

13. Babitt JL, Lin HY. Mechanisms of Anemia in CKD. J Am Soc Nephrol. 2012;23(10):1631-4.

14. Locatelli F, Aljama P, Bárány P, Canaud B, Carrera F, Eckardt K-U, et al. Revised European best practice guidelines for the management of anaemia in patients with chronic renal failure. Nephrol Dial Transplant. 2004;19 Suppl 2:ii1-47.

15. Tim Goodnough L, Comin-Colet J, Leal-Noval S, Ozawa S, Takere J, Henry D, et al. Management of anemia in patients with congestive heart failure. Am J Hematol. 2017;92(1):88-93.

16. Filippatos GS, Ahmed MI, Gladden JD, Mujib M, Aban IB, Love TE, et al. Hyperuricaemia, chronic kidney disease, and outcomes in heart failure: potential mechanistic insights from epidemiological data. Eur Heart J. 2011;32(6):712-20.

17. Ebner N, Jankowska EA, Ponikowski P, Lainscak M, Elsner S, Sliziuk V, et al. The impact of iron deficiency and anaemia on exercise capacity and outcomes in patients with chronic heart failure. Results from the Studies Investigating Co-morbidities Aggravating Heart Failure. Int J Cardiol. 2016;205:6-12.

18. Hotta C, Hiraki K, Watanabe $\mathrm{S}$, Izawa KP, Yasuda T, Osada N, et al. Knee extensor muscle strength and index of renal function associated with an exercise capacity of 5 metabolic equivalents in male chronic heart failure patients with chronic kidney disease. Clin Exp Nephrol. 2014;18(2):313-9.

19. Scrutinio D, Agostoni P, Gesualdo L, Corrà U, Mezzani A, Piepoli M, et al. Renal function and peak exercise oxygen consumption in chronic heart failure with reduced left ventricular ejection fraction. Circ J. 2015;79(3):583-91. 